\title{
A publicidade sem caráter e a estética do velamento
}

\section{Unspecified advertising and the aesthetics of veiling}

João Anzanello Carrascoza ${ }^{1}$ 


\section{Resumo}

A expansão tecnológica das últimas décadas no campo midiático levou as agências de publicidade a adotarem novas formas de produzir e veicular mensagens para as marcas anunciantes e seus produtos e serviços, como o embalde marketing, o branded content, a live experience, entre outras. Discutiremos a utilização de uma dessas estratégias publicitárias frequentemente exploradas nos tempos atuais, o product placement, apoiando-nos nas reflexões de Byung-Chul Han em sua obra $A$ salvação do belo (2019). Nossa "tese" sinaliza que a publicidade, para atender ao consumidor sem caráter (aquele no qual nada se esculpe ou se fixa), tornou-se também "lisa", graças sobretudo à sua "estética de velamento".

\section{Palavras-chave}

Comunicação publicitária, consumo, product placement, estética.

\section{Abstract}

In the last decades, the advent of technology in the media has led advertising agencies to adopt new ways of producing and delivering messages to advertising brands and their products and services, such as packaging marketing, branded content, live experience. This paper discusses the use of one of these intensely explored advertising strategies in present times, namely product placement, supporting us by Byung-Chul Han's reflections in his work The Salvation of the Beautiful (2019). Our theory signals that advertising, in order to cater to the unspecified consumer (the one in which nothing is sculpted or fixed), has also become "flat", thanks above all to its "veiling aesthetics".

\section{Keywords}

Advertising communication, consumption, product placement, aesthetics. 


\section{Esses tempos líquidos e lisos}

O conceito de liquidez, trazido por Zygmunt Bauman em algumas de suas obras, especialmente em Modernidade líquida (2001), é amplamente utilizado no campo das ciências sociais como forma de interpretar o momento histórico contemporâneo, fruto das transformações econômicas, sociais e culturais do capitalismo globalizado. Nesse estágio, a solidez das instituições e relações comerciais, bem como dos vínculos humanos - mais precisamente tratados em outro de seus livros, Amor líquido (2004) -, construções intelectuais e ideias perde espaço para o que é fluido, incapaz de manter a forma, e, em consequência, escorre, esvai e transborda.

Nesse período de fluidez, precedido então pela modernidade sólida quando as mudanças seguiam num ritmo lento, dando às sociedades humanas certa sensação de controle e segurança -, os padrões tornaram-se temporários e se liquefazem continuamente, gerando angústia, temor e violência.

Embora Bauman não tenha se detido nas questões associadas diretamente às características dessa fluidez na comunicação e tampouco na arte, seu conceito pode ser expandido para esses dois domínios. Sem se opor a ele, conquanto também sem assumi-lo, o professor sul-coreano de filosofia ByungChul Han nos propõe uma outra chave interpretativa em sua obra $A$ salvação do belo (2019) - o advento do "liso" (e a sua positividade) -, para pensarmos a estética desses tempos centrada sobretudo no universo digital. "O liso é a marca do presente... Além do efeito estético, nele se reflete um imperativo social universal. Ele corporifica a sociedade da positividade atual. O liso não quebra. Também não opõe resistência. Ele exige likes" (HAN, 2019, p. 7, grifo do autor).

Propomos aqui alargar as reflexões de Han para o sistema publicitário, que consiste em uma constelação de discursos comunicacionais, tendo nas artes uma de suas principais matrizes - e, podemos acrescentar, continua a mimetizar formas de ver e de dizer, além de procedimentos de linguagem, das mais variadas expressões artísticas. 
Constituinte da malha midiática contemporânea, o sistema publicitário vem igualmente se transformando com rapidez, em virtude das inovações tecnológicas das últimas décadas, buscando explorar de maneira ininterrupta o diálogo com os consumidores por meio das redes sociais digitais, entre outras possibilidades de interações comunicativas. Covaleski (2010) nomeia inclusive de "publicidade híbrida" certa configuração produtiva que resulta dos materiais publicitários contemporâneos e que se apoiam em três colunas: o entretenimento, a interação e o compartilhamento, possível unicamente graças à evolução da internet, a partir da consolidação da web 2.0.

As primeiras peças publicitárias, os afiches espalhados pelas ruas de Paris na Belle Époque, eram gravuras assinadas por importantes pintores, que a elas se dedicavam com o mesmo esmero e estilo dispensado às suas próprias obras. A Figura 1 apresenta um afiche de Alphonse Mucha, criado para promover os biscoitos Champenois. Dada a sua qualidade artística, a ilustração foi depois integrada às obras completas do pintor, ganhando o título de Rêverie ${ }^{2}$, sem obviamente a inscrição da marca comercial (Figura 2), como podemos ver em ambas as versões da obra.

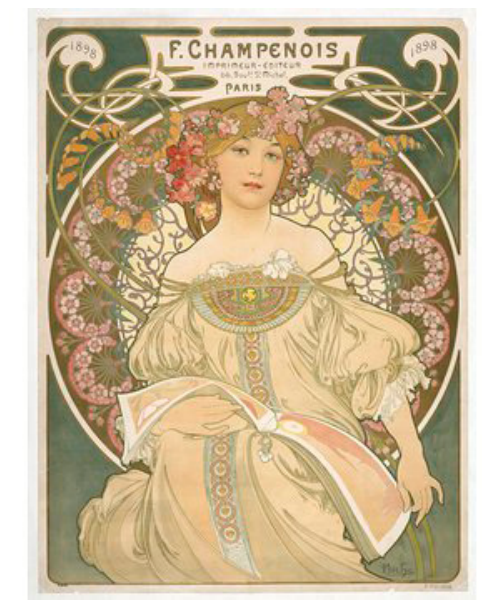

Figura 1: Afiche (1898), de Alphonse Mucha, criado para a marca de biscoitos Champenois Fonte: WikiArt. 


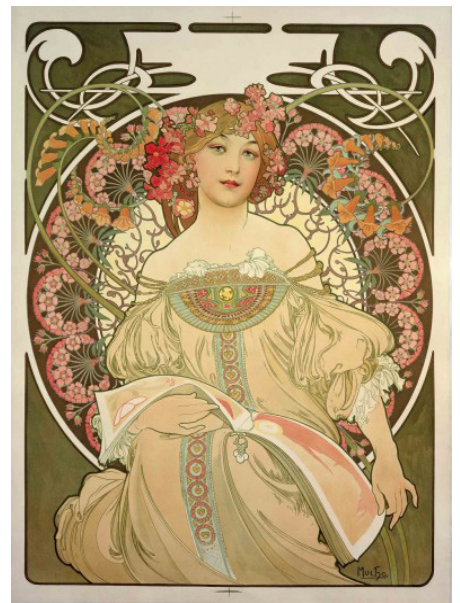

Figura 2: Rêverie (1898), sem a marca Champenois, para a qual foi originalmente criada

Fonte: Mucha Foundation.

Os formatos publicitários que se seguiram aos afiches - os anúncios, de jornal e revista - incorporaram recursos pictóricos na instância visual e literários na instância verbal. O mesmo ocorreu com os jingles produzidos para as rádios dos anos 1920 em diante e, posteriormente, para os filmes publicitários (veiculados em cinema e televisão), ao assumirem a estrutura melódica dos ritmos musicais.

Uma farta e consistente bibliografia nacional e estrangeira comprova as apropriações da arte pela publicidade, bem como iniciativas da arte que se inspiraram no mundo das marcas comerciais e dos produtos consumidos na vida cotidiana $^{3}$, como é o caso da pop art. E, da mesma maneira que a publicidade se vale de fundamentos da narrativa literária em seus comerciais, a literatura incorpora formatos publicitários, como neste conto da escritora Luana Chnaiderman (2018, p. 83), que apresenta o formato de anúncio classificado:

Tiramos os pelos da perna, da sobrancelha e do cu. Depilação completa, egípcia. Tiramos calos, peles, cutículas, buço e axilas. Tiramos os poros da pele, a pele do corpo. Esfoliação, peeling. Drenamos e modelamos. Tiramos a cor dos cabelos e dos cachos. Chapinha, progressiva, não 
usamos formol. Tiramos os pelos das costas, da barriga, rugas e marcas de expressão. Tiramos o escuro dos dentes, o torto dos dentes e os dentes do siso. Tiramos gorduras, coxas, ancas, barrigas, braços e costas. Celulite, cicatriz, tatuagem. As sardas do rosto, as estrias da perna, parte da bunda, dos seios. Uma costela. Aceitamos pagto em parcelas.

Por meio do pensamento de Han (2019) sobre o belo, pretendemos investigar como esse conceito se espraia nos modos de ver e de dizer da publicidade, além de discutir suas implicações em relação ao consumidor, visto que a comunicação publicitária on-line vem ajustando a sua estética no ambiente digital com vistas a gerar o constante engajamento do público - a sua finalidade é fazer saber (por meio de argumentos, vetor apolíneo) e/ou fazer crer (pela sensibilização, vetor dionisíaco), conforme demonstramos (CARRASCOZA, 2004).

\section{O belo contemporâneo, o liso, o digital}

Han reúne pequenos, densos e interligados ensaios em $A$ salvação do belo (2019), abordando a estética do liso, o ideal do belo, a sua política e a sua criação, além de temas correlatos - a beleza como verdade e como reminiscência, entre outros. Interessa-nos, em seu pensamento, a sua conceituação do belo, guia de nossa discussão. O autor assim define o conceito de belo:

O belo é algo oculto. Para a beleza, o encobrimento é essencial. A transparência não se dá com a beleza. A beleza transparente é um oxímoro. A beleza é necessariamente uma aparência. Nela reside uma opacidade. Opaco quer dizer sombreado. A revelação desencanta e o destrói. Assim, o belo é indesvelável segundo sua essência. (HAN, 2019, p. 43 , grifo do autor)

A ideia de que o belo é essencialmente "indesvelável" leva Han a abordar o que, no outro extremo, se revela em sua total plenitude, sendo explicitado ao máximo, ou seja, a pornografia. Nesse sentido, para ele, a pornografia é a figura oposta ao belo.

Podemos dizer que a beleza na publicidade aspira ao erótico, ao que não se mostra de saída, ao que atrasa, como já apontamos em outro estudo 
(CARRASCOZA, 2014) nos filmes publicitários a revelação do produto só se dá no final, como um detalhe expressivo da narrativa, não atravessa toda a ação da trama, move-se justamente ao contrário - é o principal (o produto) que se torna secundário nas histórias da publicidade, ocupando poucos segundos (os últimos) do tempo de duração do audiovisual:

[...] o objetivo dessa estratégica, de inserir o detalhe no fim do comercial, no instante em que se atinge o ápice da narrativa - o desfecho da história -, é gerar a identificação e, por meio desta, o consequente contágio. A empatia, assim, se estabelece, pela estética da sugestão. (CARRASCOZA, 2014, p. 48-49)

Se "esconder, atrasar e despistar são estratégias espaço-temporais do belo", conforme afirma Han (2019, p. 44), o mesmo ocorre nos filmes publicitários, em sua forma canônica, com o desenvolvimento do enredo ocupando quase todo o seu tempo (trinta segundos ou um minuto tradicionalmente na veiculação para televisão) e a inserção do logotipo da empresa anunciante e a respectiva enunciação de seu posicionamento apenas no final. O posicionamento, aliás, tangencia o seu slogan, que opera como moral da história narrada, momento único em que explicita o que pretende, o seu fazer saber ou o fazer crer, junto ao público.

Se "ser-belo é fundamentalmente ser-velado" (HAN, 2019, p. 45), não é por acaso que a publicidade, igualmente, vai "construir" suas peças audiovisuais mantendo, até o instante derradeiro da narrativa, o velamento de seu intuito - a promoção do produto, serviço ou marca.

Em outras palavras, Han (2019, p. 46) nos diz que o "invólucro é mais essencial do que o objeto velado", o que nos leva a pensar na "opção" adotada pela publicidade, à semelhança da arte, pelo ocultamento em sua narrativa de seu conteúdo principal, em convergência com o ponto de vista de Fernando Pessoa, poeta e também publicitário em seu tempo, que dizia: "o princípio primeiro da publicidade é esconder seu objetivo" (FERREIRA, 1986, p. 148).

No entanto, a recente evolução tecnológica, que disseminou o hábito do telespectador de "zapear", ou seja, buscar pelo controle remoto outros produtos 
midiáticos, em especial durante os intervalos comerciais que veiculam os filmes publicitários de feitio tradicional, obrigou o sistema publicitário a explorar outras formas de interação no domínio das produções culturais midiáticas, notadamente as de entretenimento.

É nesse contexto que passa a ser adotado com mais frequência o product placement - inserção de produtos ou logomarcas de anunciantes em filmes, documentários, seriados, telenovelas etc., de forma integrada em seu contexto ficcional. A presença publicitária se dá, portanto, fora dos breaks, infiltrando-se precisamente na "lisura" da história de seu "hospedeiro", não em seu assumido e costumeiro material fílmico, reconhecido como tal pelo público, mesmo que o seu intuito mercadológico, como vimos, seja revelado só ao fim.

Essa é, pois, uma das formas pelas quais a publicidade se adapta à estética do liso, "fenômeno genuinamente contemporâneo", como preconiza Han (2019, p. 27). Em outras palavras: o conteúdo da publicidade está velado ao longo da produção cultural fílmica, "revelando-se" em momentos seletivos e, ainda assim, não explicitamente - à semelhança de seios femininos num vestido decotado -, seguindo a estratégia do velamento, que, na concepção de Han (2019, p. 46), "erotiza o texto".

Sim, o rasgo, a quebra, a brecha constituem o erótico (HAN, 2019, p. 49). E é precisamente o que vemos nas ações de product placement, nas quais, de súbito, o produto (ou a marca) aparece encaixado nas dobras do espaço diegético, como explicitaremos a seguir.

\section{Product placement, estética e velamento}

Numerosos são os exemplos de product placement no âmbito das produções audiovisuais, que aqui nos interessam em especial, não obstante a sua prática se espraiar igualmente pelo tecido de outras "mídias", como nas narrativas literárias, conforme aponta Ribaric (2019, p. 24), ao investigar, em consulta a vários estudiosos do assunto, as mutações desse conceito: 
[...] no Japão do século XVIII, Santo Kyoden, um popular escritor de ficção gesaku e kibyōshi (livros de imagens satíricas), sharebon (livros espirituosos sobre moda), kokkeibon (ficção cômica), hanashibon (livros humorísticos) e yomihon (livros de leitura), também conhecido por ilustrar suas obras, inseria informações sobre sua própria loja de tabaco nas histórias que escrevia.

Na literatura brasileira, realçamos (CARRASCOZA, 1999) o caso pioneiro de Monteiro Lobato, que inseriu em sua obra O Sacy Pererê mensagens de marcas anunciantes que colaboraram financeiramente no custeio da primeira edição do livro, como a fabricante de máquinas de escrever Remington e a de chocolates Lacta (Figura 3), entre outras.
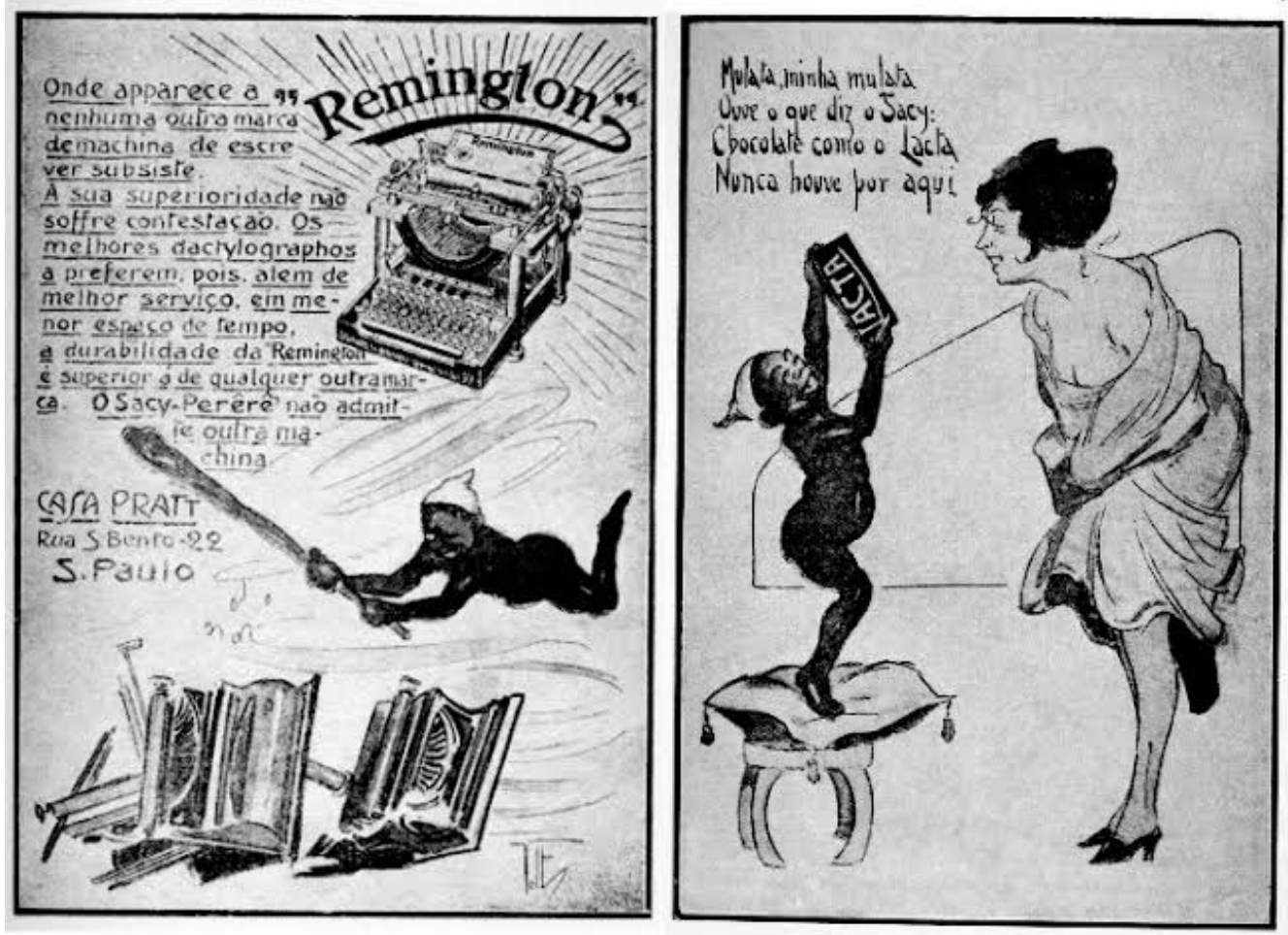

Figura 3: Anúncios das marcas Remington e Lacta na primeira edição de O Sacy Pererê (1918) Fonte: O Sacy Pererê, 1918.

Na esfera do cinema e da televisão, segundo Russell (1998), há três maneiras de concretizar a utilização do product placement: 1) a inserção unicamente visual da marca do anunciante (ou da embalagem do produto) na cena; 2) a inserção verbal/ auditiva, quando o nome da marca (ou produto) é enunciado pelos personagens; e 3) a inserção imbricada no enredo, o chamado plot placement, que vai além da 
simples aparição (visual) ou menção (verbal/ auditiva), sendo parte essencial e determinante do próprio enredo, portanto um elemento compulsório que se molda na narrativa ficcional. Independentemente do número de aparições e/ou menções verbais da marca/ produto, ao nosso ver, essas são invariavelmente janelas discretas - ou falaciosamente indiscretas - por meio das quais a publicidade se materializa. Elas se abrem para que a mensagem publicitária acenda a sua luz e, num ato contínuo, apague-a, devolvendo a atenção do telespectador ao enredo da narrativa, sob pena de se descaracterizar como brecha e, em consequência, quebrar a estética do liso.

Numerosos são os exemplos, nas últimas décadas, de product placement na história do cinema mundial, especialmente o hollywoodiano, como o do chocolate Reese's em E.T.: o extraterrestre (1982), da Coca-Cola (entre outras marcas) em Blade Runner (1982), da bola de vôlei Wilson e da transportadora FedEx em Náufrago (2000), do automóvel Ford Explorer em O terminal (2004), e, mais recentemente, do leite fermentado Yakult na produção da Netflix Para todos os garotos que já amei (2018). Este último caso, inclusive, apresenta numa única cena as três modalidades de product placement mencionadas: visual, verbal/ auditiva e plot placement (Figura 4).

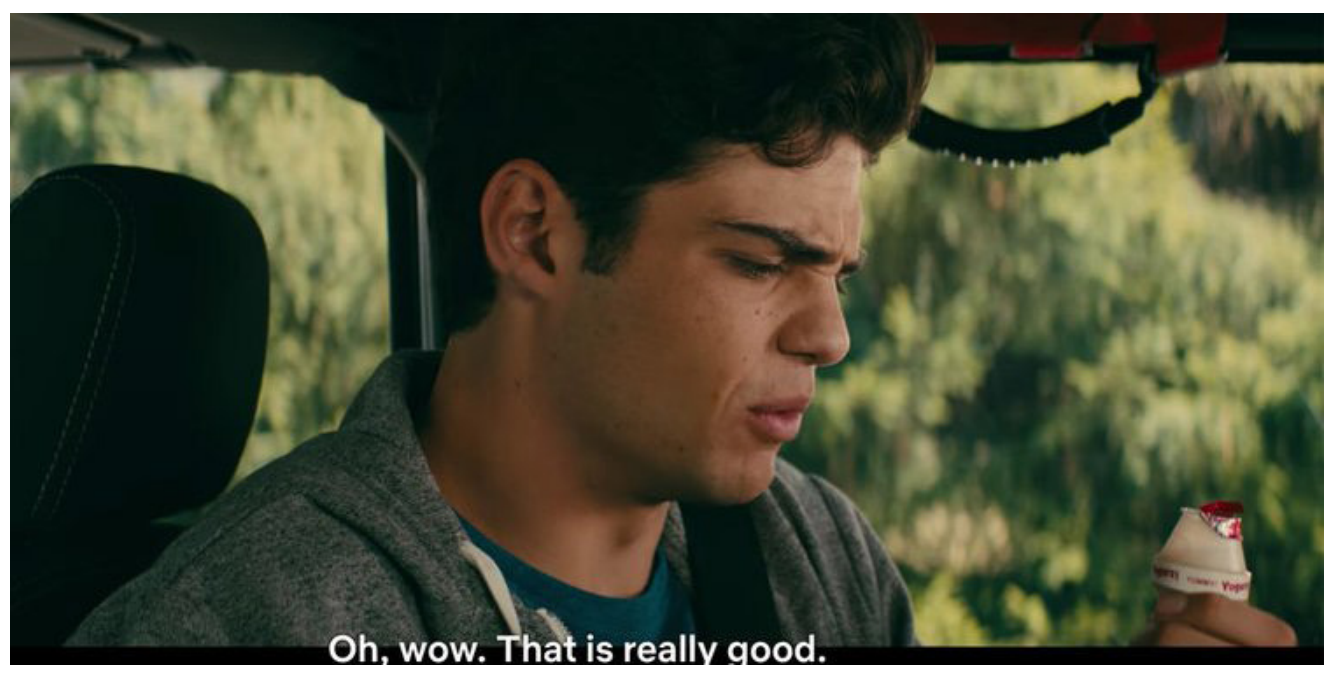

Figura 4: Product placement, de Lactobacilos Yakult, no filme Para todos os garotos que amei (2018) Fonte: Netflix. 
Além de listar casos, sabendo que alguns já foram amplamente estudados, ainda que sob outra abordagem, interessa-nos observar como o velamento publicitário de fato se concretiza. Uma vez que o consumo das produções audiovisuais passou também a ser on-line, notamos a expansão do product placement de "enredo".

Se no início de sua utilização, as marcas apareciam de forma visual e/ou verbal/ auditiva, a opção mais frequentemente adotada nos filmes e séries nos últimos anos é a inserção da mensagem publicitária no corpo da história, velando o máximo possível o seu intuito e revelando-o de modo mais "natural". Não mais a janela discreta (ou indiscreta), mas apenas uma fresta.

Vejamos um exemplo não apenas clássico de product placement na história do cinema norte-americano, mas cuja utilização se deu de forma diferenciada - o filme De volta para o futuro (1985). Nesse longa-metragem, a marca da rede de postos de gasolina Texaco avulta em várias das "décadas" pelas quais a narrativa atravessa, coincidentes com a sua trajetória real no mercado. O logotipo da Texaco aparece quando o tempo diegético do filme se detém nos anos 1955 (Figura 5), 1985 (Figura 6) e 2015 (Figura 7), conforme estudos de Helena e Pinheiro (2012).

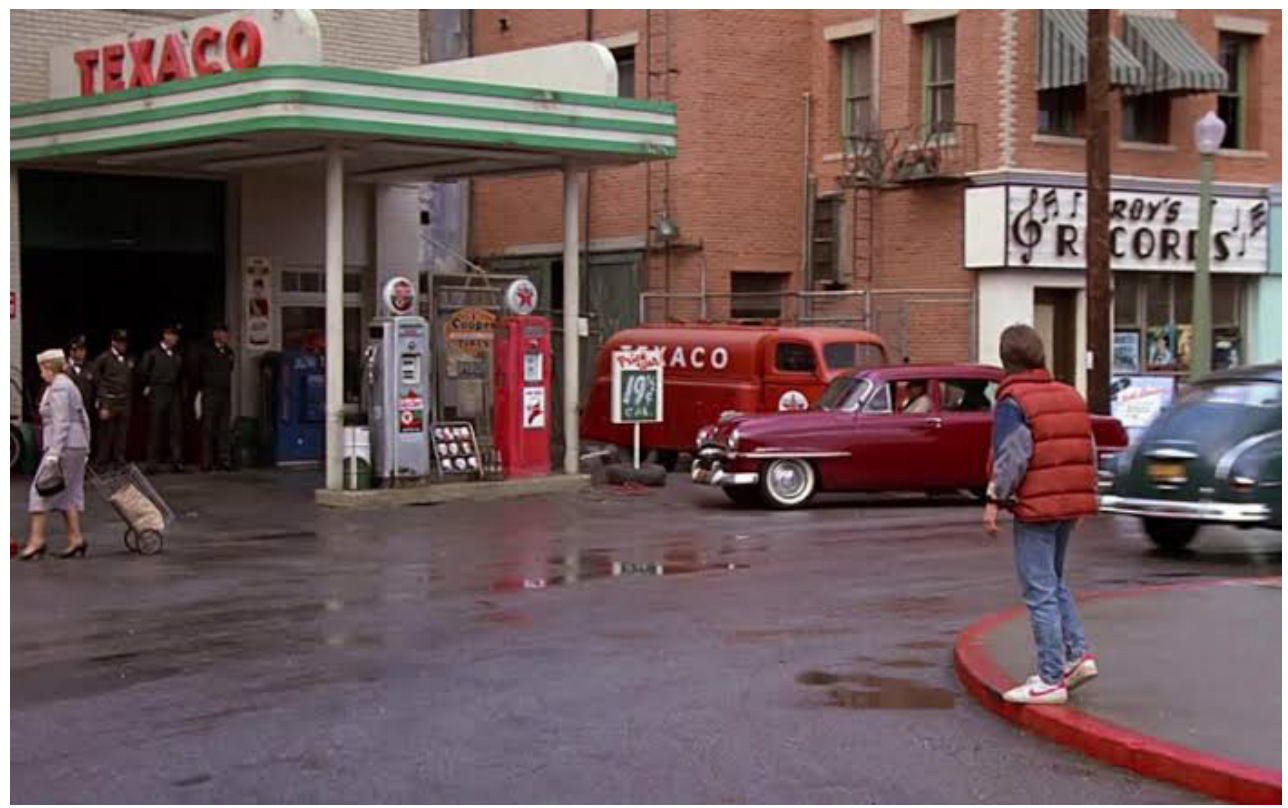

Figura 5: Logotipo da Texaco em 1955 no filme De volta para o futuro (1985) Fonte: De volta para o futuro. 


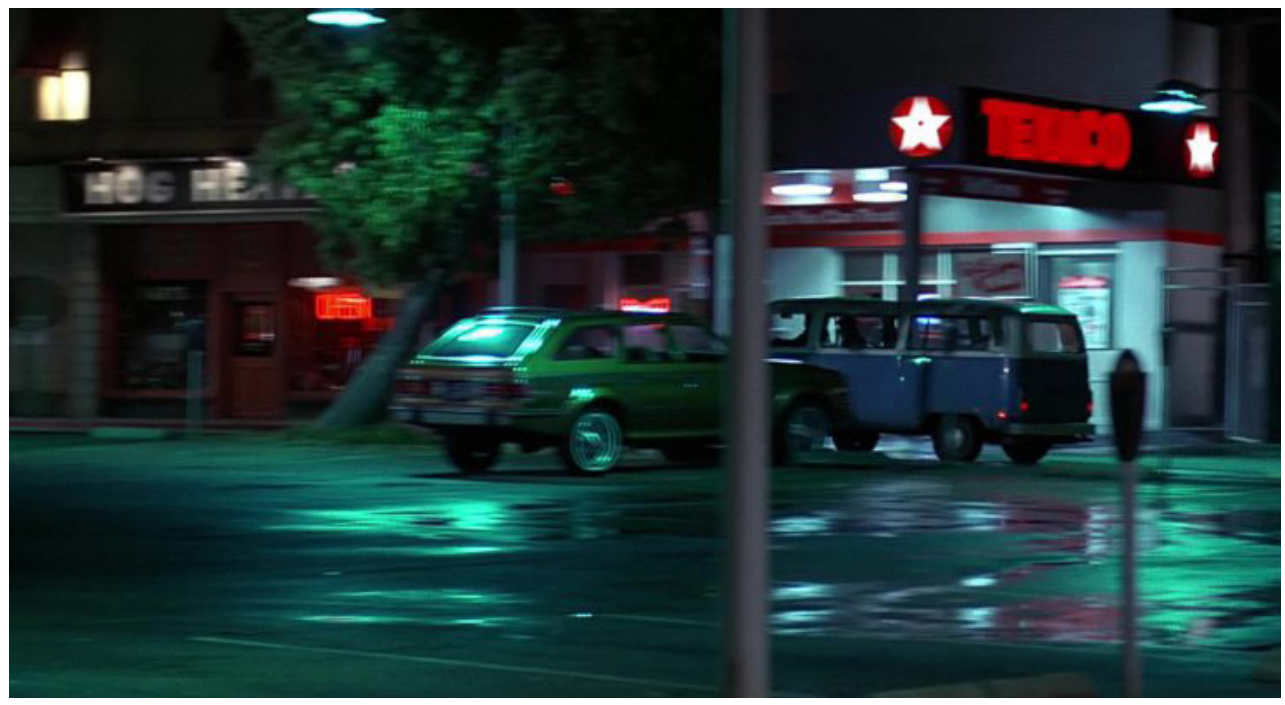

Figura 6: Logotipo da Texaco em 1985 no filme De volta para o futuro (1985) Fonte: De volta para o futuro.

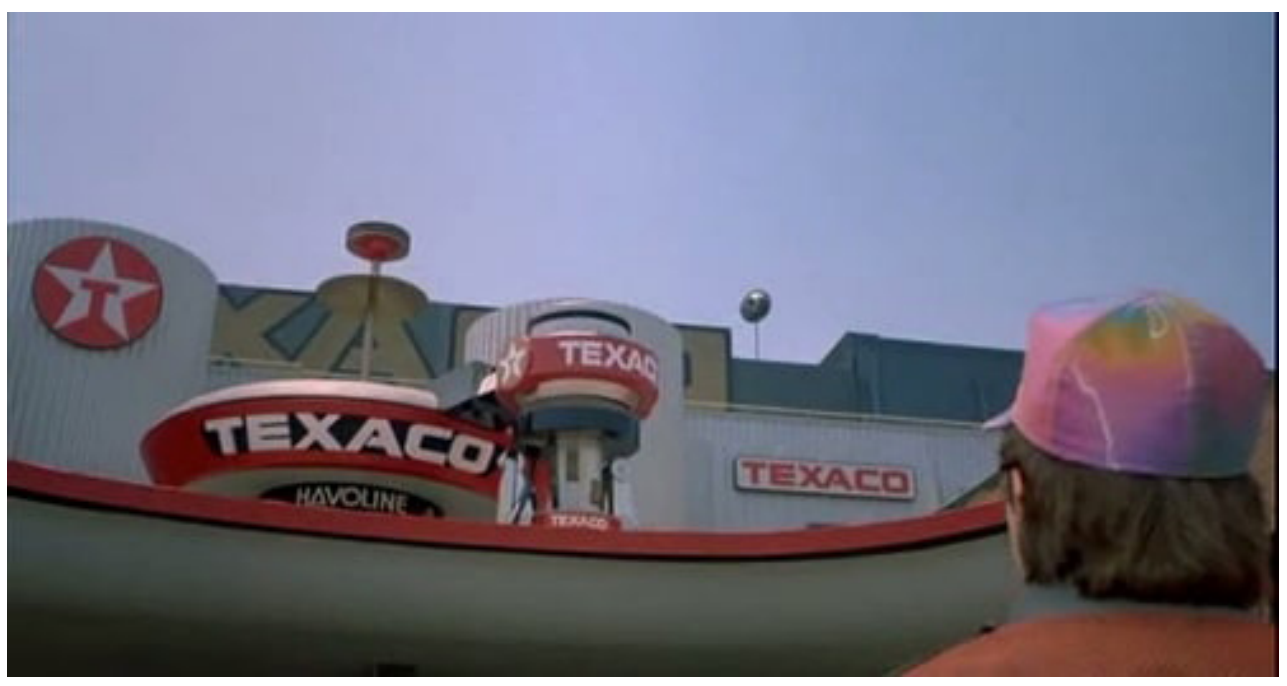

Figura 7: Logotipo da Texaco em 2015 no filme De volta para o futuro (1985) Fonte: De volta para o futuro.

A janela publicitária se abre em três momentos, correspondentes à identidade visual da Texaco em cada momento retratado, evidenciando que essa marca há muito atua expressivamente no comércio de combustível para veículos - ela possui passado, presente e insinua um porvir.

Talvez não por acaso a ficcionista espanhola Rosa Montero, em seu livro Lágrimas na chuva (2014), cuja ação se passa no ano de 2109, apresente como 
publicidade do futuro a mulher-anúncio da Texaco-Repsol, espécie "aprimorada" do homem-sanduíche (uma das primeiras formas da publicidade), que carrega no peito uma tela que emite mensagens publicitárias dessas duas empresas em uma só (ainda hoje) poderosas em sua atividade comercial. Seria uma suspeita de que o petróleo continuaria sendo a mais importante fonte de energia um século à nossa frente, ou apenas uma ironia da escritora?

Sigamos, agora, com um caso mais recente, dos muitos encontrados em séries produzidas originalmente pela plataforma Netflix, e que, em nossa concepção, vem fazendo do product placement um item compulsório de seu modelo de negócio. Selecionamos o último episódio da segunda temporada de A Casa de Papel (2018), série sobre assalto a um banco, no qual temos a cena de fuga dos ladrões num caminhão da marca de cerveja Estrella Galicia (Figura 8).

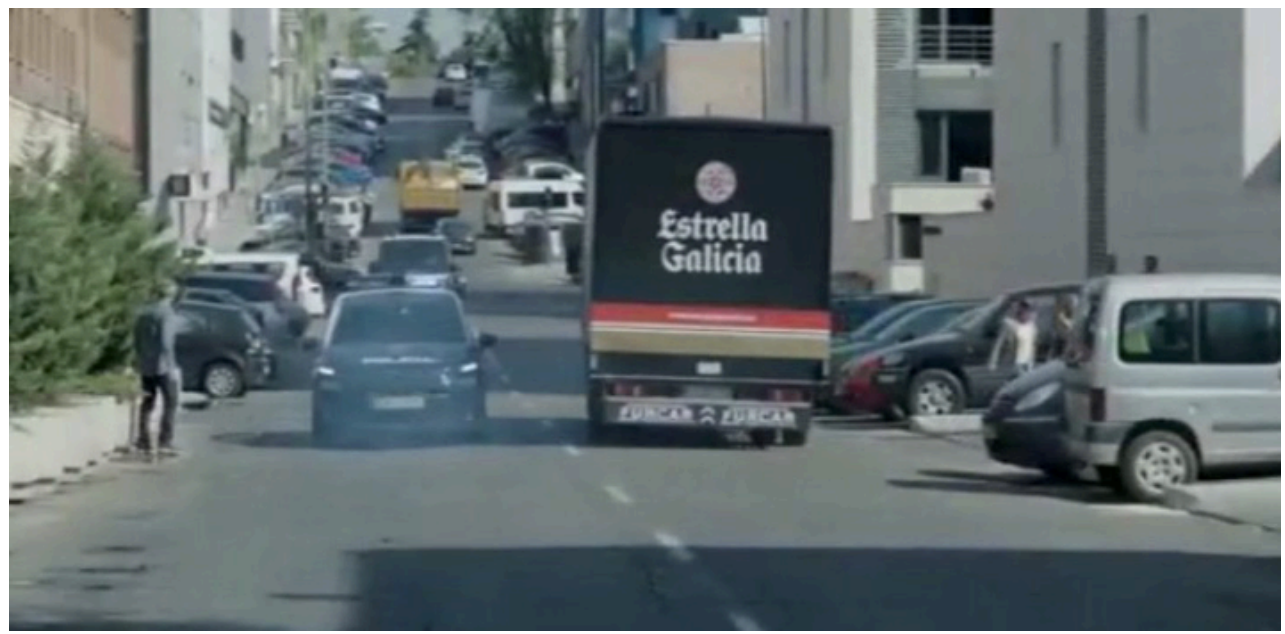

Figura 8: Caminhão de cerveja Estrella Galicia, série A Casa de Papel (2018) Fonte: Netflix.

Em consonância com as ideias de Han (2019) em relação à estética do liso, temos aqui, de súbito, uma brecha (ou um rasgo) no desfecho da história, pela qual a logomarca do produto se mostra, qualquer que seja a categoria (das três) de product placement escolhida, conforme a proposta de Russel (1998). Em teoria, a ação publicitária (visual, verbal/ auditiva ou entranhada no enredo) deveria operar de forma favorável, já que objetiva promover o produto. 
Nesse exemplo, contudo, acreditamos que a inserção da marca da cerveja é feita numa situação discutível, o que resultaria um "product displacement". Ainda assim, ela não resulta numa explicitação, pois o conteúdo narrativo ocupa a quase totalidade do tempo do episódio e o logotipo da Estrella Galicia aparece - como esperado - tão somente numa fissura da diegese, que, de imediato, recompõese, mantendo a soberania do liso.

A esse respeito, vamos nos apoiar em Safatle (2009), quando define como posicionamento bipolar de marca essa nova etapa da retórica da publicidade, pela qual se dá a mercantilização não mais dos valores exclusivos dos produtos, os seus diferenciais, as suas particularidades técnicas, a sua singularidade em suma, mas a de valores contrários: "O que aparentemente seria um erro crasso de posicionamento revela-se uma astúcia. Por um lado, isso permite ao consumidor identificar-se com a marca, sem, necessariamente, identificar-se com um de seus pólos" (SAFATLE, 2009, p. 104-105).

A sociedade contemporânea permite às marcas, atentas às identificações hegemônicas mas também às minoritárias, a enunciação da norma e igualmente da transgressão. Os consumidores, nos lembra Safatle (2019, p. 107) são instados tanto para as identificações fixas (no extremo, estereotipadas) quanto para as irônicas, "nas quais, a todo momento, o sujeito afirma sua distância em relação àquilo que ele está representando ou, ainda, em relação a suas próprias ações".

Esse padrão retórico do consumo se plasma na estética do liso acrescentemos -, já que o liso dispensa os relevos, os pontos de resistência. Norma e transgressão são linhas presentes, que se alternam no processo da tessitura publicitária (essa, por sua vez, reconfigura-se para atender a insatisfação daqueles nem sempre identificados com o sinal positivo).

Dessa forma, não nos parece descabida a possibilidade de que a aparição de um copo de papel da rede mundial de cafés Starbucks (Figura 9) no meio de um episódio da última temporada da série Game of Thrones (2019), veiculada pela HBO, cuja ação se passa em outro tempo e lugar que não o mundo contemporâneo, e anunciada como uma falha cinematográfica, não seja uma ação consciente de 
bipolaridade da marca por meio do product placement. Matérias jornalísticas (PATTEN, 2019; RAI, 2020) realizadas com membros da produção, como os diretores do episódio David Benioff e D. B. Weiss, esclarecem que não, mas não haveria aqui a erotização que o liso permite por meio de fendas na narrativa?

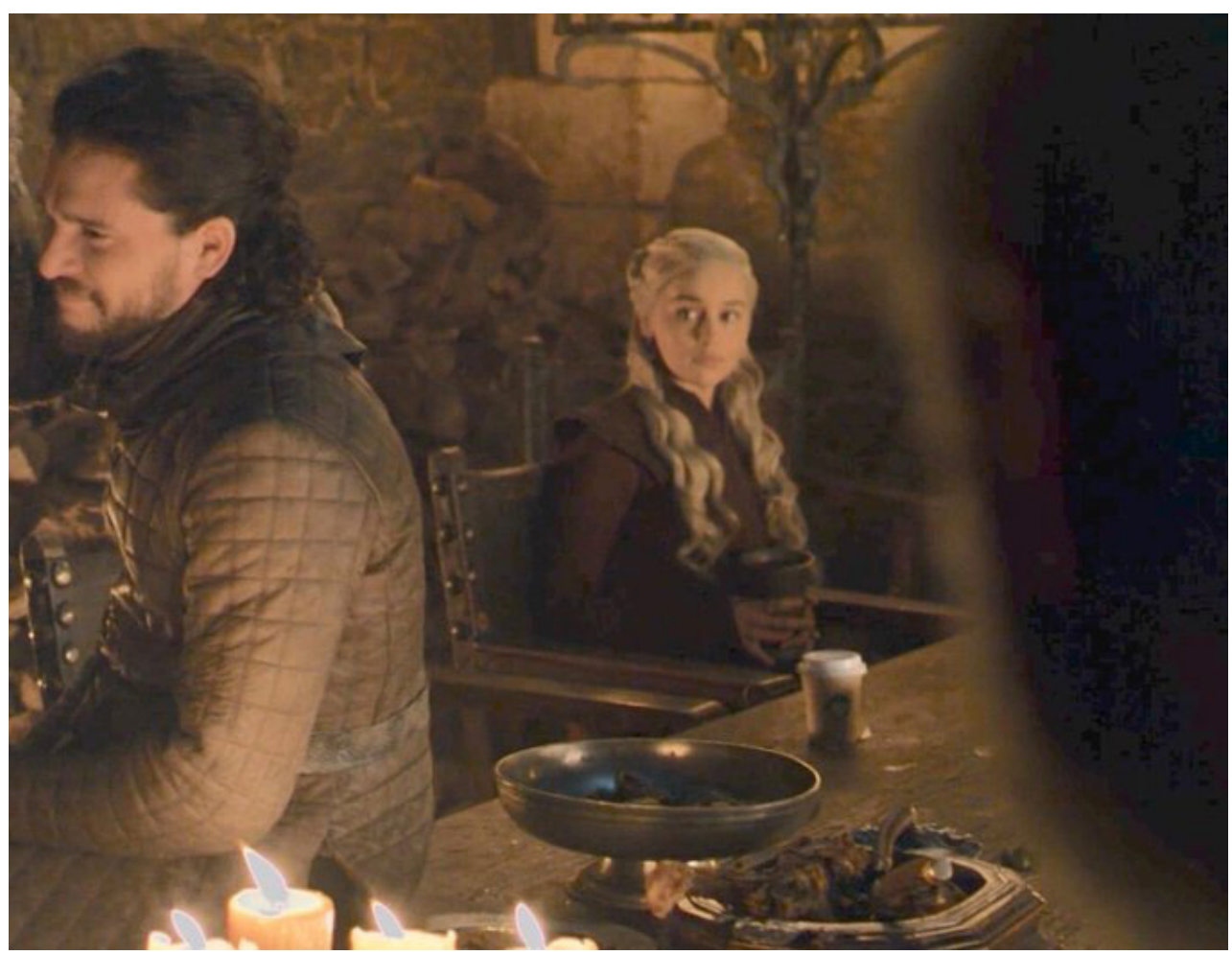

Figura 9: Copo de café da marca Starbucks em cena da série Game of Thrones (2019), da HBO Fonte: Game of Thrones.

O product placement, portanto, é uma das formas pelas quais a publicidade, para manter-se como mediadora entre a produção e o consumo ante a nova ordem comunicacional - catalisada pelos avanços tecnológicos e culturais -, viu-se impulsionada a ampliar-se a fim de melhorar a adaptação de sua retórica ao ambiente das mídias digitais e, como efeito, manter-se fiel ao liso estético.

Tal cenário, em que as horas gastas pelos consumidores na internet vêm aumentando, tanto quanto o consumo de conteúdos audiovisuais on-line (HOOTSUITE, 2019), leva-nos obrigatoriamente a rever a atual dinâmica publicitária. 


\section{O velado e o consumidor sem caráter}

Se antes o acesso à publicidade pelo product placement se dava no momento em que o espectador assistia ao filme numa tela de cinema ou num canal de televisão, ou seja, numa hora determinada e, ainda, num tempo não distante, em videocassetes e em computadores por meio de DVDs, nos últimos anos o público pode fazê-lo a qualquer hora com um aparelho conectado à internet (pelo streaming). As novas formas de consumo modelam, consequentemente, um outro perfil - ou caráter - de consumidor.

Para Han (2019, p. 72), "o caráter significa originalmente o signo gravado, marcado no fogo, indelével. A imutabilidade é sua característica principal". Ele cita Carl Schmitt, para quem a água é um elemento sem caráter, não é possível nele nenhuma marcação sólida. O mar é sem caráter, já que a origem da palavra caráter vem do grego diarassein, fixar, esculpir, gravar. Nesse sentido, o professor sul-coreano de filosofia afirma: "Solidez e consistência não são propícias para o consumo. Consumo e duração se excluem mutuamente. São as inconsistências e a fugacidade da moda que o aceleram. A cultura do consumo diminui a duração. Caráter e consumo são opostos" (HAN, 2019, p. 73).

As dezenas, para não dizer centenas, de filmes e seriados produzidos pela Netflix - que, se antes reinava solitariamente, enfrenta agora concorrentes como a HBO Go, a Amazon Prime Video e a Apple TV, entre outras plataformas de streaming, só para ficarmos nesse tipo de consumo de conteúdos audiovisuais vão se acumulando até transbordarem na disputa pelo interesse do consumidor.

Esse consumidor, conectado, remete-nos novamente à fluidez, na concepção de Bauman (2001), com a qual iniciamos nossa reflexão. Uma novidade no campo do entretenimento se sobrepõe à outra e o lançamento de um produto cultural gera uma euforia, logo substituída pela chegada de outro, a tecnologia voltada à comunicação on-line, hoje de última geração e amanhã de penúltima.

Assim, para Han (2019, p. 73), "a mídia digital assemelha-se ao mar sem caráter, no qual não é possível traçar linhas ou marcas sólidas". E mais: "O 
consumidor ideal é um homem sem caráter. Essa falta de caráter torna possível um consumo indiscriminado" (HAN, 2019, p. 73, grifo do autor).

Como não há intervalo comercial na Netflix, o product placement se estabelece não só como ação publicitária anti-intrusiva, alinhada à estética do liso, mas também como um trunfo para se viabilizar. Para as marcas anunciantes, por sua vez, consiste numa alternativa comunicacional estratégica, um modo de atingir o grande público de assinantes dessa plataforma.

A Netflix permite a criação de perfis de consumidores, para que o algoritmo de programação Ihes recomende assertivamente as séries e os filmes mais condizentes com seu histórico de consumo audiovisual. É provável que, assim, a empresa esteja tentando dar ao consumidor um traço (sólido) de caráter - certamente para manter ou ampliar a fidelidade ao seu acervo em contínua expansão.

Contudo, como aponta o autor,

O caráter sólido não consegue se conectar bem. Não é conectivo ou comunicativo. Na era da conexão, globalização e comunicação, um caráter sólido é apenas obstáculo e desvantagem. A ordem digital celebra um novo ideal. Chama-se o homem sem caráter, o liso sem caráter. (HAN, 2019, p. 75, grifo do autor)

Tomando tal afirmação como base, podemos dizer que a publicidade, nessa era do digital, é também desprovida de caráter. As marcas, ao contrário, para que existiam como materialidades, precisam possuir algum caráter - o que não é paradoxal, visto que parte de sua personalidade é fixa e parte é mutável, como aponta Fontenelle (2002, p. 250).

\section{A distinção pela retenção}

Com o advento do universo digital, ou da "sociedade em rede", como propôs Castells (2009), e, por conseguinte, com o início do reinado do "liso", a força do sistema publicitário poderia ser atenuada, perdendo o seu posto de retórica principal do consumo. 
Mas, como na canção "Esteticar (Estética do plágio)" (2001), de Tom Zé, Vicente Barreto e Carlos Rennó, a publicidade não é "um caboclo tolo boboca/ um tipo de mico cabeça-oca/ raquítico típico jeca-tatu/ um mero número zero um zé à esquerda/ pateta patético lesma lerda/ autômato pato panaca jacu". Muito pelo contrário, ela é adepta, como na própria expressão de um dos versos dessa composição, da "estética do arrastão" - ou seja, por meio do "liso", arrasta a sua mensagem, ora pelos meios tradicionais, ora pelas frestas que o product placement (ou mesmo o product displacement) cava nas narrativas audiovisuais de entretenimento. Assim, continua envolvendo o consumidor com ênfase discursiva no vetor dionisíaco, visando o fazer crer com as suas ações veladas.

O consumidor - incluindo todos nós - vive, então, à mercê de sua própria atenção, também lisa, tentando escorregar do caudal de ofertas que não o interessam - ou não são suficientemente atrativas no momento.

Han (2019, p. 107) afirma que "a beleza é vacilante, atrasada. Belo não é um brilho momentâneo, mas uma fosforescência quieta. E nessa retenção que consiste sua distinção". Assim, valeria indagarmos se, por meio do product placement, que em suas utilizações inaugurais se comportou como um brilho momentâneo no meio da trama audiovisual (o detalhe expressivo), a publicidade não vem se modificando para, em respeito à estética do liso, ser também uma fosforescência quieta. O consumidor, por seu turno, estará satisfeito com a sua própria falta de caráter?

\section{Referências}

BAUMAN, Z. Amor líquido: sobre a fragilidade dos laços humanos. Rio de Janeiro: Zahar, 2004.

BAUMAN, Z. Modernidade líquida. Rio de Janeiro: Zahar, 2001. 
CARRASCOZA, J. A. A evolução do texto publicitário. São Paulo: Futura, 1999.

CARRASCOZA, J. A. Estratégias criativas da publicidade. São Paulo: Estação das Letras e Cores, 2014.

CARRASCOZA, J. A. Razão e sensibilidade no texto publicitário. São Paulo: Futura, 2004.

CASTELLS, M. A sociedade em rede. Rio de Janeiro: Paz e Terra, 2009.

CHNAIDERMAN, L. Os animais domésticos e outras receitas. São Paulo: Perspectiva, 2018.

COVAleskI, R. Publicidade híbrida. Curitiba: Maxi, 2010.

ESTETICAR (Estética do Plágio). Belo Horizonte: Letras, 2001. Disponível em: https://www.letras.mus.br/tom-ze/338211. Acesso em: 12 jan. 2020.

FERREIRA, A. M. (org.). Fernando Pessoa, o comércio e a publicidade. Lisboa: Cinevoz: Lusomedia, 1986.

FONTELELLE, I. O nome da marca. São Paulo: Boitempo, 2002.

HAN, B. A salvação do belo. Petrópolis: Vozes, 2019.

HELENA, R. S.; PINHEIRO, A. J. A. Muito além do merchan! Como enfrentar o desafio de envolver as novas gerações de consumidores. Rio de Janeiro: Elsevier, 2012.

HOOTSUITE. Relatório da situação digital global em 2019. [S. I.]: Hootsuite, 2019. Disponível em: https://hootsuite.com/resources/digital-in-2019. Acesso em: 18 dez. 2019. 
MONTERO, R. Lágrimas na chuva. Rio de Janeiro: Nova Fronteira, 2014.

PATTEN, D. HBO reveals the truth behind 'Game of Thrones' on-screen coffee cup mistake. Deadline, Nova York, 6 maio 2019. Disponível em: https://bit.ly/37meVgb. Acesso em: 10 jan. 2020.

RAI, B. New streaming service launches in UAE for the performing arts: catch performances from the Royal Opera House, the Bolshoi Ballet and more. Gulf News, Dubai, 10 jun. 2020. Disponível em: https://bit.ly/2XMPXDF. Acesso em: 11 jan. 2020.

RÊVERIE (1898). Praga: Mucha Fundation, c2020. Disponível em: https://bit. Iy/2XPNKHH. Acesso em: 11 nov. 2019

RIBARIC, M. E. A evolução dos conceitos de product placement nas produções audiovisuais. Comunicação \& Inovação, São Caetano do Sul, v. 20, n. 42, p. $22-35,2019$.

RUSSELL, C. A. Towards a framework of product placement: theoretical propositions. Advances in Consumer Research, Provo, v. 25, p. 357-362, 1998. Disponível em: https://bit.ly/2UvOCiC. Acesso em 18 dez. 2019.

SAFLATE, V. Identidades flexíveis como padrão da retórica de consumo. In: CAEPM (org.). Bravo mundo novo: novas configurações da comunicação e do consumo. São Paulo: Alameda, 2009. p. 83-112.

submetido em: 18 jan. 2020 | aprovado em: 15 maio 2020 